\title{
Modelos de gestión pedagógica: Factores de participación, cambio e innovación en centros educativos costarricenses
}

\author{
Pedagogical Management Models: Factors of Participation, Change, and Innovation in \\ Costa Rican Educational Centers
}

\section{Modelos de Gestão Pedagógica: Fatores de participação, mudança e inovação nos centros educacionais da Costa Rica}

Evelyn Chen-Quesada Universidad Nacional Heredia, Costa Rica

evelyn.chen.quesada@una.cr http://orcid.org/0000-0002-5280-3134

Virginia Cerdas-Montano

Universidad Nacional

Heredia, Costa Rica

norma.cerdas.montano@una.cr http://orcid.org/0000-0003-1705-4630

\section{Satya Rosabal-Vitoria}

Universidad Nacional Heredia, Costa Rica

satya.rosabal.vitoria@una.cr http://orcid.org/0000-0002-1450-7836

Recibido • Received • Recebido: 19 / 11 / 2018

Corregido • Revised • Revisado: 11 / 02 / 2020

Aceptado • Accepted • Aprovado: 01 / 04 / 2020

\begin{abstract}
Resumen: El estudio presenta los resultados de investigación derivados del proyecto de extensión Modelos de gestión pedagógica (MGP), realizado con centros educativos públicos de las provincias de Heredia, Alajuela y San José, bajo la responsabilidad de la División de Educación para el Trabajo (DET), del Centro de Investigación en Docencia y Educación (CIDE) de la Universidad Nacional, Costa Rica (UNA). El objetivo es analizar la influencia del desarrollo de los modelos de gestión pedagógica en los centros educativos participantes, entre el 2005 al 2013, en el ámbito educativo costarricense; así como determinar la relación entre las variables: participación y cambio y la categoría; innovación y su efecto sobre el colectivo docente y administrativo. Esta investigación utiliza un método mixto (Creswell, 2009), porque es abordada desde un enfoque cuantitativo y cualitativo. Lo cualitativo se estudia desde lo fenomenológico, al reflexionar sobre el sentido y significado que aporta el grupo de participantes al proceso de MGP, en relación con las innovaciones metodológicas en el aula, espacios colectivos y organización administrativa. Mientras que el enfoque cuantitativo se realiza con un
\end{abstract}


http://doi.org/10.15359/ree.24-2.16

ROR: https://ror.org/01t466c14 Universidad Nacional, Costa Rica

http://www.una.ac.cr/educare

educare@una.cr

diseño ex post facto y transversal, porque responde a la percepción del colectivo participante, explora elementos y factores que influyen en la participación y la actitud, frente al cambio en el desarrollo de los MGP. El grupo de estudio está compuesto por 72 participantes del proyecto, 78,6\% docentes y $21,4 \%$ personal directivo. Entre los principales resultados se destacan que la participación y cambio son necesarios para avanzar hacia modelos pedagógicos más acordes con la realidad institucional. Los MGP contribuyen a la innovación metodológica y son producto de un trabajo participativo y colaborativo, pensado desde las necesidades e intereses de los contextos educativos. La principal implicación de la investigación es brindar a personal académico e investigador un referente basado en evidencia que pueda ser consultado en futuros estudios en materia de calidad de la gestión pedagógica en centros educativos costarricenses.

Palabras claves: Modelos de gestión; actitud frente al cambio; liderazgo pedagógico; innovaciones pedagógicas; participación.

Abstract: This study describes the results of a study derived from the extension project Models of Pedagogical Management (MGP in Spanish), conducted in public schools of the provinces of Heredia, Alajuela and San José, under the responsibility of the Division of Education for Work (DET), from the Center for Research in Teaching and Education (CIDE) of the National University (UNA). The aim is to analyze the influence of the development of pedagogical management models in the participating schools between 2005 and 2013, in the Costa Rican educational field. It also aims to establish the relationship between the variables "participation and change" and the category "innovation" and its effect on the teaching and administrative group. This study applies a mixed methodology (Creswell, 2009) since it implements a quantitative and qualitative approach. From the qualitative approach, phenomenology is considered by reflecting on the meaning and sense that the group of participants brings to the MGP process concerning methodological innovations in the classroom, collective spaces, and administrative organization. While the quantitative approach is carried out with an ex post facto and cross-sectional design because it responds to the perception of the participating group, it explores elements and factors that influence participation and the attitude towards the change in the development of the MGP. The study group comprises 72 project participants, $78.6 \%$ are teachers, and $21.4 \%$ are directors. Among the significant results are that participation and change are necessary to move towards pedagogical models more in line with the institutional reality. MGP contributes to methodological innovation and is the product of participatory and collaborative work, designed from the needs and interests of educational contexts. The main implication of the research is to offer academics and researchers a reference based on evidence that can be consulted in future studies on the quality of pedagogical management in Costa Rican educational centers.

Keywords: Management models; attitude towards change; pedagogical leadership; pedagogical innovations; participation.

Resumo: O estudo apresenta os resultados da pesquisa decorrente do projeto de extensão Modelos de Gestão Educacional (PGM), feitos com escolas públicas nas províncias de Heredia, Alajuela e San José, sob a responsabilidade da Divisão de Educação para o Trabalho (DET), do Centro de Pesquisa em Ensino e Educação (CIDE) da Universidade Nacional (UNA). O objetivo é analisar a influência do desenvolvimento de Modelos de Gestão Pedagógica nos centros educativos participantes entre 
2005 e 2013 no campo educacional da Costa Rica, bem como determinar a relação entre as variáveis; participação, mudança e categoria; inovação e seus efeitos no grupo de ensino e administrativo. $\mathrm{O}$ presente estudo responde a uma metodologia mista (Creswell, 2009), uma vez que é elaborado a partir de uma abordagem quantitativa e qualitativa. A partir da abordagem qualitativa, a fenomenologia é estudada refletindo sobre o significado que o grupo de participantes traz para o processo MGP, em relação às inovações metodológicas em sala de aula, espaços coletivos e organização administrativa. Embora a abordagem quantitativa seja realizada com um desenho retrospectivo e transversal, porque responde à percepção do grupo participante e explora elementos e fatores que influenciam a participação e a atitude em relação à mudança no desenvolvimento do POP. O grupo de estudo é composto por 72 participantes do projeto, $78,6 \%$ professores e $21,4 \%$ diretores. Entre os principais resultados estão a participação e a mudança necessárias para avançar em modelos pedagógicos mais alinhados com a realidade institucional. O POP contribui para a inovação metodológica e é produto do trabalho participativo e colaborativo, concebido a partir das necessidades e interesses dos contextos educacionais. A principal implicação da pesquisa é fornecer aos acadêmicos e pesquisadores uma referência baseada em evidências que possam ser consultadas em estudos futuros sobre a qualidade da gestão pedagógica em centros educacionais da Costa Rica.

Palavras chaves: Modelos de gestão; atitude em relação à mudança; liderança pedagógica; inovações pedagógicas; participação.

\section{Introducción}

La División de Educación para el Trabajo (DET) tiene, en su oferta, la formación de personal administrador educativo en el ámbito nacional, con un perfil de formación en liderazgo pedagógico y disposición a colaborar desde diferentes espacios a solucionar necesidades de las poblaciones más vulnerables y a elevar la calidad de la oferta educativa costarricense.

Es en este sentido, el proyecto de extensión Modelos de gestión pedagógica brinda al personal directivo y docente en ejercicio una alternativa de acompañamiento que responda a las necesidades particulares de cada contexto. Durante más de diez años este proyecto genera espacios de diálogo y reflexión sobre el quehacer institucional, por lo que se hace necesario valorar la influencia del proyecto de extensión en los centros participantes desde las categorías: participación, cambio e innovación.

El siguiente estudio responde al objetivo general sobre el análisis de la influencia del desarrollo de los modelos de gestión pedagógica en los centros educativos participantes entre el 2005 al 2013 en el ámbito educativo costarricense. De dicho objetivo se señalan tres objetivos específicos que contemplan la identificación del nivel de participación de las personas que conforman el centro educativo, además de determinar la actitud frente al cambio de las personas que conforman el centro educativo y se identifican de las innovaciones en el espacio de aula, espacios colectivos y organización administrativa como resultado del desarrollo del proyecto Modelo de gestión pedagógica. 
Para atender lo anterior se plantea el siguiente problema de investigación: ¿Cuál es la influencia del desarrollo del modelo de gestión pedagógica en los centros educativos participantes entre el 2005 al 2013?

El estudio se formula desde un enfoque mixto, el cual se sustenta en los aportes de Creswell, (2009) por su abordaje en el enfoque cuantitativo y cualitativo, y su alcance exploratorio-descriptivo.

Esta investigación se plantea en el marco del proyecto de extensión Modelos de gestión pedagógica desarrollado por el Centro de Investigación en Docencia en Educación y la División de Educación para el Trabajo (DET) desde el año 2005 y hasta el 2014. Entre las regiones educativas participantes en este proceso se encuentran la de San José, Alajuela y Heredia.

\section{Antecedentes}

Esta es una investigación inédita en el tanto que permite analizar los factores de participación, cambio e innovación en el desarrollo de MGP en los centros educativos participantes entre el 2005 al 2014, por ser un estudio producto del proyecto de extensión Modelos de gestión pedagógica desarrollado por la DET-CIDE-UNA desde el año 2005 y hasta el 2014 en cual solo se ha implementado en Costa Rica. Entre las regiones educativas participantes en este proceso se encuentran la de San José, Cartago, Alajuela y Heredia.

Cabe indicar que en un estudio previo realizado por Cerdas Montano, Marín Calderón et ál. (2008) sobre modelos de gestión pedagógica, en zonas de atención prioritaria, resaltó el papel directivo como líder al permitir que su personal tuviera una mayor participación en la realización de MGP, mientras que aquellos centros que no contaron con este liderazgo presentaron deserción y el proceso se tornó complejo para ejecutar. Además, señaló que: "El trabajo en equipo es esencial en la implementación de innovaciones" (p. 25)

En el estudio de Rosabal Vitoria et ál. (2013), Modelos de gestión pedagógica en la escuela primaria: Un aporte en la calidad de la educación, refiere que los procesos pedagógicos deben gestionarse desde el centro educativo, partiendo de sus propias necesidades e intereses y atendiendo el contexto en el cual se desarrollan, para promover, con ello, el sentido de pertenencia de los actores sociales.

De acuerdo con lo anterior, el actual estudio permite ahondar sobre factores de participación que podrían desarrollarse como parte de una cultura escolar, que promueva la innovación en el campo pedagógico y administrativo. Esto, a su vez, permite una dinámica que facilita cambios en los centros educativos, generando procesos de resistencia que son parte de la dinámica de cambio, pero que a su vez deben de ser observados y atendidos de manera oportuna por las personas directivas. 


\section{Marco teórico}

Cada centro educativo es un sistema en sí mismo con características propias e interdependientes que le dan identidad. Esta morfogénesis brinda la capacidad para modificarse y transformar su estructura básica, la cual se ve influenciada por tres principios: la participación, la actitud frente al cambio y la innovación. Por lo tanto, el MGP no es ajeno a esta dinámica de interacciones en el desarrollo e implementación de sus etapas, fases y pasos, tal y como se puede observar en la Tabla 1.

Tabla 1: Etapas, fases y pasos del MGP

\begin{tabular}{|c|c|c|}
\hline ETAPA & FASE & PASOS \\
\hline \multirow{6}{*}{ Coordinación } & \multirow{2}{*}{ Sensibilización } & Empoderamiento del equipo coordinador \\
\hline & & Convencimiento de la comunidad educativa \\
\hline & \multirow{2}{*}{ Análisis de contexto } & Reconociendo el contexto \\
\hline & & Comprensión del contexto \\
\hline & \multirow{2}{*}{ Rol institucional } & Identificación de la acción sustantiva \\
\hline & & Factibilidad desde la administración de recursos institucionales \\
\hline \multirow{5}{*}{ Organización } & \multirow{3}{*}{ Planificación } & Identificación de principios y valores \\
\hline & & Identificación de visión y misión institucional \\
\hline & & Definiendo proyectos institucionales \\
\hline & \multirow{2}{*}{ Accionando esperanzas } & Implementación de los proyectos \\
\hline & & Sostenibilidad y motivación del proceso \\
\hline Retroalimentación & Seguimiento evaluación & Monitoreo y seguimiento \\
\hline
\end{tabular}

Nota: Tomado de Cerdas Montano, Chen Quesada et ál. (2018, p. 79).

\section{Participación}

Estudios llevados por Feito Alonso (2011) sobre la importancia de la participación en los procesos escolares han permitido comprender que cuanta mayor colaboración, mayor el nivel de logro; por supuesto que la participación implica contar con espacios de reflexión, trabajo en equipo, compromiso, liderazgo, comunicación, entre otros.

La participación es una acción social dirigida a democratizar las decisiones y que los resultados, producto de estas, sean compartidos y valorados por la comunidad educativa, de manera que brinden pertinencia e identidad. La participación es "un término polisémico cuyo 
significado puede ir desde la mera recepción de información a la adopción de decisiones con trascendencia en la vida de los centros" (Feito Alonso, 2011, p. 9).

Espacios de reflexión para la toma de decisiones, están orientados al crecimiento intelectual, social, personal y humano en relación con la comunidad educativa, a fin de identificar lo esencial y significativo de la enseñanza y del aprendizaje. Por ello, los espacios de reflexión se generan con la clara intención de repensar el quehacer educativo y así mismo tomar decisiones participativas (Domènech y Viñas, 1999).

La participación de la familia, se comprende como aquellas acciones programadas o planificadas para que exista interacción entre ellas y la comunidad educativa en la toma de decisiones. Unesco (2004) ha señalado:

En lo concreto, participar implica: opinar, tomar ciertas decisiones, proponer y disentir en los diversos espacios de la institución educativa. Proponer aquellos propósitos curriculares que guiarán la enseñanza de sus hijos e hijas, dar ideas respecto de los recursos requeridos y acerca de las formas de obtenerlos, haciéndose parte de la gestión. (p. 26)

Participación en equipo de trabajo, se relaciona con el sentido de la misión y visión cumplidas de cada individuo en relación con su trabajo colaborativo. El trabajo en equipo "es la comprensión y compromiso con las metas del grupo por parte de todos los miembros del equipo" (Lussier y Achua, 2008, p. 262).

Nivel de compromiso en la participación, es el grado de responsabilidad del colectivo en el cumplimiento de metas y objetivos del centro educativo. "El compromiso implica ponerse a disposición para soñar colectivamente y orientar las acciones de los demás en las áreas en las que las competencias individuales sean requeridas" (Pereira Santana, 2013, p. 109).

Liderazgo en la participación, son aquellas habilidades, conductas y acciones destinadas a liderar procesos educativos con clara colaboración de la comunidad, es el mecanismo que promueve los liderazgos y los potencia; en este sentido, Murillo Torrecilla (2006) indica del liderazgo:

Conlleva una labor transformadora, pues no se limita a trabajar en las condiciones existentes y con las metas dadas, sino en ir alterando aquellas condiciones del centro y del aula para que mejoren la educación ofrecida y las prácticas docentes en el aula. (p. 237)

Participación colectiva e individual, la colectiva es la interacción entre las personas a fin de obtener productos conjuntos, mientras que la individual son los aportes de cada individuo en sí mismo, por cuanto, "la participación eficaz y satisfactoria debería estar caracterizada por los principios de corresponsabilidad, cooperación, coordinación, autoridad y democracia" (Antúnez, 2000, p. 91). 
Comunicación en la participación, son los procesos de trasmisión de conocimiento o información con significado para el colectivo involucrado, que permite, no solo hacer llegar el mensaje, sino su comprensión dentro del contexto educativo. Al respecto, Puig et ál. (2003) señalan que "la participación democrática en la escuela necesita un espacio donde la palabra y el diálogo sean los protagonistas. Un momento en el que el alumnado y el profesorado se planteen los temas de trabajo y vida escolar" (p. 20).

Participación curricular, son aquellas acciones y reflexiones destinadas a la comprensión conjunta del colectivo participante en torno al currículo. Gauthier (2011, citado por Amadio et ál., 2015) plantea:

El currículo como ... producto de un proceso de selección y organización de "contenidos" relevantes por las características, las necesidades y aspiraciones de la sociedad y que abarca las finalidades y los objetivos de la educación, los planes y programas de estudio. (p. 4)

Participación en el desarrollo profesional, son aquellos procesos de formación informal o formal destinados al crecimiento personal y profesional, tanto individual como colectivo, por cuanto, "el concepto de actualización conlleva necesariamente la idea de lograr un 'ajuste'. Por lo tanto, hemos de entenderla como un proceso activo en el que la evolución es la condición más importante y necesaria de cumplir" (Sanguino Mejía, 1990, p. 53).

\section{Actitud frente al cambio}

Se conceptualiza como aquellos comportamientos que enfrenta o vive una comunidad educativa frente al cambio y que influyen positiva o negativamenteen el desarrollo o implementación de nuevos procesos educativos, según "un sinnúmero de expertos y estudiosos recomienda considerar el cambio como un proceso, no un producto" (Lussier y Achua, 2011, p. 435).

En este proceso se pueden presentar resistencias, cambios en la cultura organizacional, procesos de acompañamiento, comunicación entre otros.

Resistencia frente al cambio, es una manifestación psicofísica individual o colectiva de rechazo ante fenómenos nuevos. Las personas se resisten al cambio, por cuanto, "el cambio trastoca el status quo y con frecuencia genera tensión, incomodidad y, para algunos, incluso perturbaciones" (Lussier y Achua, 2008, p. 396).

Cultura organizacional frente al cambio, son todas las experiencias, sentires, procesos identitarios, entre otros, que vive la organización educativa producto de los cambios que se enfrenta. Por consiguiente, "el cambio es imperativo si las organizaciones pretenden crecer y prosperar en el entorno actual y futuro, hacer cambios, en especial los importantes" (Lussier y Achua, 2008, p. 392). 
http://doi.org/10.15359/ree.24-2.16

ROR: https://ror.org/01t466c14 Universidad Nacional, Costa Rica

http://www.una.ac.cr/educare

educare@una.cr

Procesos de acompañamiento frente al cambio, son todas las acciones destinadas a bajar los niveles de incertidumbre hacia lo desconocido. Bolívar (2012) ha señalado que la teoría del cambio educativo expone tres tipos de acompañamiento:"1. Táctica, se adoptan determinadas respuestas para resolver un problema específico, normalmente limitadas en el tiempo ... 2. Estratégica ... se adopta un plan sistemático. 3. Construir capacidades ... su foco es la mejora de los procesos de enseñanza y aprendizaje" (pp. 132-133).

Comunicación ante el cambio, son todos los medios, canales, mecanismos o estrategias que se utilizan para mantener informados y en contacto a miembros de una comunidad ante el cambio; por tanto, "es el proceso de transmisión de información y significado. La verdadera comunicación se presenta solo cuando todas las partes entienden el mensaje (la información) desde la misma perspectiva (el significado)" (Lussier y Achua, 2011, p. 191).

Las familias ante el cambio, mantener a las familias informadas juega un papel preponderante en la asimilación de los nuevos procesos educativos. No obstante, y por la importancia que tienen las familias como eje social, se pueden hacer esfuerzos adicionales para lograr una mayor participación de estas, por cuanto, "participar implica que el poder que posee la institución o el Programa Educativo es compartido entre los profesionales, dirigentes y tutores" (Unesco, 2004, p. 26).

Percepción de nivel de apoyo del MEP, entendida esta como la apreciación que tiene la comunidad educativa, en relación con el apoyo que recibe el centro por parte del MEP. Cabe destacar que una de sus funciones es la asesoría y supervisión para hacer cumplir las normas con las que se rigen las instituciones educativas.

\section{Innovación}

La innovación escolar responde a una necesidad sentida en la comunidad educativa y que conlleva la movilización de recursos y participación colectiva, conducidos a la renovación o creación para las transformaciones en materia curricular. Esta innovación puede desarrollarse en los ámbitos de la gestión y la academia; persigue el mejoramiento del desempeño docente, administrativo y del estudiantado. De acuerdo con Segura Bonilla (2010) "Las innovaciones son interactivas, sociales y surgen de las relaciones de los diferentes miembros de la sociedad y de esta con la naturaleza. Por tanto, se entiende que las innovaciones no surgen espontáneamente... son la acumulación de un proceso de aprendizaje" (p.132).

La teoría de la investigación describe tres subcategorías de innovación, a saber: metodológica en el aula, en espacios colectivos y en la organización administrativa.

Innovaciones metodológicas en el aula, son todas aquellas propuestas metodológicas novedosas que el cuerpo docente implanta para efectos de desarrollar una mediación pedagógica en coherencia con el proyecto educativo curricular del centro.

\section{8}

Evelyn Chen-Quesada, Virginia Cerdas-Montano y Satya Rosabal-Vitoria

Los artículos de la Revista Electrónica Educare del Centro de Investigación y Docencia en Educación de la Universidad Nacional, Costa Rica, se comparten bajo términos de la Licencia Creative Commons: Reconocimiento, № Comercial, Sin Obra Derivada 3.0 Costa Rica. Las autorizaciones adicionales a las aquí delimitadas se pueden obtener en el correo: educare@una.cr 
Importa destacar que el eje de acción de un centro educativo son los procesos de aprendizaje, por cuanto los esfuerzos que se realizan van direccionados al mejoramiento de la calidad de la oferta educativa (Bolívar, 2012).

Innovaciones en espacios colectivos, se refiere a todos aquellos espacios que son utilizados por la comunidad educativa y que tienen relación con el desarrollo del proyecto educativo. Los esfuerzos del colectivo por hacer cambios en estos espacios deben responder a la visión, misión y filosofía institucional. La integración de estos espacios al currículo escolar es una de las condiciones necesarias para el éxito de la innovación en el centro educativo. Se conceptualizan, según Chen Quesada y Vargas Jiménez (2007) como espacios docentes, recreativos, servicios, gestión, circulación, trabajo colectivo y comunes.

Innovaciones en la organización administrativa, se refiere a las acciones novedosas que las personas que tienen a cargo la gestión del centro desarrollan para favorecer los objetivos y metas establecidas en el proyecto educativo.

\section{Metodología}

El presente estudio responde a una metodología mixta (Creswell, 2009), ya que es abordada desde un enfoque cuantitativo y cualitativo. Desde el enfoque cualitativo, se estudia lo fenomenológico al reflexionar sobre el sentido y significado que aporta el grupo de participantes al proceso de MGP, en relación con las innovaciones metodológicas en el aula, espacios colectivos y organización administrativa.

Mientras que el enfoque cuantitativo se realiza con un diseño ex post facto y transversal, porque responde a la percepción del colectivo participante y explora elementos y factores que influyen en la participación y la actitud frente al cambio en el desarrollo de los MGP.

Es importante destacar que desde esta metodología mixta el problema de investigación es complejo, ya que tiene una realidad objetiva y una realidad subjetiva, en este caso, la realidad objetiva se midió desde un enfoque cuantitativo y la realidad subjetiva se analizó por medio de un enfoque cualitativo. Las investigadoras, por ser parte del proceso de extensión, se convierten, a su vez, en informantes claves para el análisis de las respuestas desde la observación de campo que históricamente se desarrolló durante ocho años. Hernández Sampieri et ál. (2014) mencionan que"así, para ... 'capturar' ambas realidades coexistentes (la realidad intersubjetiva), se requieren tanto la visión 'objetiva' como la 'subjetiva'. (p. 536)

A su vez, esta investigación tiene un alcance exploratorio-descriptivo (Hernández Sampieri et ál., 2010), ya que, en el contexto educativo costarricense, es el primer estudio que realiza un análisis de la influencia del desarrollo de los MGP, desde la perspectiva de sus participantes y describe elementos de innovación, cambio y participación que permiten una comprensión integral del proceso implementado. 
http://doi.org/10.15359/ree.24-2.16

ROR: https://ror.org/01t466c14 Universidad Nacional, Costa Rica

http://www.una.ac.cr/educare

educare@una.cr

A continuación, se describen las categorías, subcategorías, variables y subvariables que fueron parte de esta investigación, ver Tabla 2.

Tabla 2: Categorías, variables, subcategorías y subvariables de la investigación

\begin{tabular}{|c|c|c|}
\hline Categorías & Subcategorías & Definición conceptual \\
\hline $\begin{array}{l}\text { Innovaciones que se } \\
\text { dinamizaron a partir } \\
\text { del desarrollo del MGP }\end{array}$ & $\begin{array}{l}\text { - Metodología en el aula } \\
\text { - Espacios colectivos } \\
\text { - Organización administrativa }\end{array}$ & $\begin{array}{l}\text { Se puede entender como un conjunto de resultados de } \\
\text { procesos sistemáticos, sociales y acumulativos que gene- } \\
\text { ran nuevos conocimientos y aprendizajes, los cuales son } \\
\text { introducidos a lo largo del tiempo, y generan referentes } \\
\text { acumulativos e históricos, capaces de crear nuevas gene- } \\
\text { raciones para aumentar las capacidades de aprendizaje y } \\
\text { transmisión del conocimiento de la totalidad de sus ac- } \\
\text { tores sociales participantes (Segura Bonilla, 2010). }\end{array}$ \\
\hline
\end{tabular}

\begin{tabular}{|c|c|c|}
\hline Variables & Subvariables & Definición conceptual \\
\hline $\begin{array}{l}\text { Nivel de participación } \\
\text { en el desarrollo del MGP }\end{array}$ & $\begin{array}{l}\text { - Espacios de reflexión } \\
\text { - Toma de decisiones } \\
\text { - Familiar } \\
\text { - Equipos de trabajo } \\
\text { - Nivel de compromiso } \\
\text { Liderazgo } \\
\text { - Colectiva e individual } \\
\text { - Nivel de comunicación } \\
\text { - Curricular } \\
\text { - Desarrollo profesional }\end{array}$ & $\begin{array}{l}\text { La participación es una acción social dirigida a } \\
\text { democratizar las decisiones y que los resultados } \\
\text { producto de estas sean compartidos y valorados } \\
\text { por la comunidad educativa, al brindar pertinencia e } \\
\text { identidad (Feito Alonso, 2011). }\end{array}$ \\
\hline $\begin{array}{l}\text { Los factores de actitud } \\
\text { frente al cambio que } \\
\text { influyeron sobre el } \\
\text { desarrollo del MGP }\end{array}$ & $\begin{array}{l}\text { - Resistencia } \\
\text { - Comunicación } \\
\text { - Proceso de acompañamiento } \\
\text { - Familias } \\
\text { - Cultura organizacional } \\
\text { - Ministerio de Educación }\end{array}$ & $\begin{array}{l}\text { Se conceptualiza como aquellos comportamientos } \\
\text { que enfrenta o vive una comunidad educativa frente } \\
\text { al cambio y que influyen positiva o negativamente en } \\
\text { el desarrollo o implementación de nuevos procesos } \\
\text { educativos. Es importante destacar el cambio como } \\
\text { proceso y no como producto (Lussier y Achua, 2011). }\end{array}$ \\
\hline
\end{tabular}

Nota:Elaboración propia, tomando en cuenta las categorías, variables, subcategorías y subvariables de la investigación.

Según Hernández Sampieri et ál. (2010), no se pueden asumir procesos predeterminados para el desarrollo de este tipo de estudio (Figura 1), sin embargo, sí se identifican las fases del diseño de la investigación.

Para el análisis cualitativo de la primera categoría"Innovaciones que se dinamizaron a partir del desarrollo del MGP" se llevaron a cabo las siguientes tareas por parte de la investigación:

1. Formulación de categoría central para cada una de las secciones agrupadas.

2. Formulación de subcategorías para cada categoría. 
3. Se organizó por cada una de las subcategorías las respuestas dadas según cada caso.

4. Se elabora un cuadro resumen para cada categoría central.

En cuanto al análisis cuantitativo se estructuraron un total de 59 ítems: 11 de información general, 48 en la escala Likert. Se realizó un análisis estadístico para cada uno de las respuestas brindadas.

Figura 1: Indica las fases del diseño de investigación

Fase A Planteamiento del problema, objetivos e insrumentos

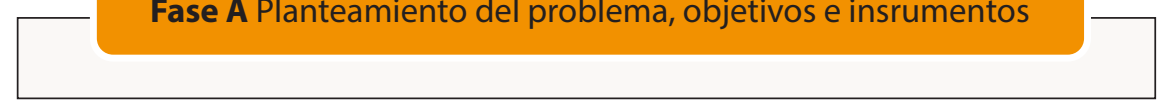

Fase B Selección y ubicación de las personas participantes

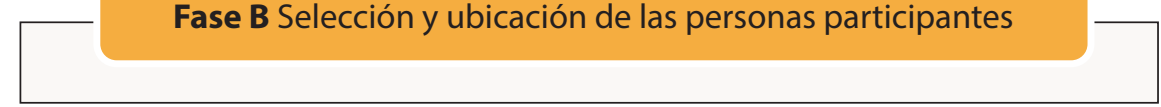

Fase C Aplicación, recolección de datos y análisis de datos

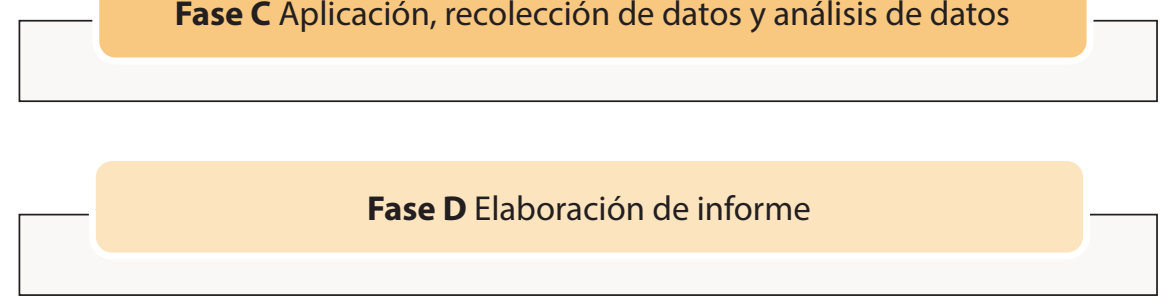

Nota: Elaboración propia.

\section{Muestra intencional}

Por ser el estudio exploratorio-descriptivo se seleccionó una muestra intencional de 72 individuos. Los criterios utilizados para la selección de la muestra son el juicio de las personas con experiencia y conocimiento con respecto a la población de personal docente y directivo que ha participado exclusivamente en el proyecto de MGP. Además, se consideró si las personas participantes laboraban o no en la institución durante alguna de las etapas del desarrollo del MGP, así como el tipo de puesto que estaban ocupando en ese momento (administrativo o docente) y si habían recibido alguna capacitación sobre MGP.

\section{Participantes}

De 72 participantes, $78.6 \%$ son docentes y $21.4 \%$ directivos. El $84.7 \%$ mujeres y el $15.3 \%$ hombres. La edad del colectivo oscila entre los 26 a 60 años. La edad del tiempo laborado en el 
sistema educativo oscila entre 1 a 30 años, destaca un 38\% de personas que tienen entre 0 a 5 años de laborar. Con respecto a los grados académicos, 52.8\% licenciatura, 11.1\% bachillerato, 33.3\% maestría y $2.8 \%$ doctorado. El tipo de nombramiento es $80.6 \%$ en propiedad y $19.4 \%$ interino. El $91.7 \%$ labora en primaria, el $6.9 \%$ en preescolar y un $1.4 \%$ en secundaria. El puesto que ocupan es de $20.8 \%$ dirección y $76.4 \%$ docencia, $2.8 \%$ no responde. Se observa que provienen de diferentes tipos de direcciones escolares, con una clara concentración en las direcciones tres, cuatro y cinco.

\section{Instrumento}

La recolección de datos utiliza un cuestionario en línea que se aplicó en agosto del 2017. Este instrumento está compuesto de dos bloques (uno con preguntas cerradas y otro con preguntas abiertas). El primer bloque se compone de tres partes, la primera recolecta datos generales de los participantes, tales como: sexo, edad, grado académico, tipo de centro educativo, tipo de puesto, tipo de dirección, años de laborar en la institución, tipo de nombramiento, última capacitación en MGP y si participó en la construcción de MGP. La segunda y tercera parte con una escala tipo Likert para marcar la frecuencia de las categorías: participación y actitud frente al cambio. Califica en una escala del 1 al 5, donde 1 es nunca, 2 rara vez, 3 de vez en cuando, 4 algunas veces y 5 siempre. En la segunda parte se aplicaron 28 ítems sobre nivel de participación y en la tercera parte se aplicaron 20 ítems sobre actitud frente al cambio. Los datos en algunos de los gráficos como en los resultados hacen referencia a la media aritmética o promedio del conjunto de $n$ respuestas dadas por el grupo participante sobre la escala utilizada con el fin de mostrar el punto de equilibrio de la distribución del conjunto de ítems a la muestra aplicada. Una vez obtenidos los datos en una hoja de cálculo se realizan los distintos análisis estadísticos.

En el segundo bloque del cuestionario se formulan preguntas abiertas relacionadas en la primera instancia sobre con la innovación pedagógica y metodológica en el desarrollo del MGP a nivel del aula, espacios colectivos y organización administrativa. Este bloque contiene 9 secciones con una pregunta abierta en cada una. Esta parte del cuestionario permite medir datos de carácter cualitativo, para efectos de clasificar cada una de las respuestas por categorías que se agrupan según el tipo de respuesta abierta brindada de forma individual. Para la agrupación de cada una de las respuestas se presentan cuatro tablas resumen de secciones que se conformaron en el cuestionario según las subcategorías y, de esta forma, se organiza la información para su respectivo análisis.

\section{Resultados, análisis y discusión}

Con los datos obtenidos en el estudio se procede a organizar e interpretar los resultados según tres variables: factores de participación, actitud frente al cambio e innovaciones en el desarrollo de los MGP.

\footnotetext{
12 Evelyn Chen-Quesada, Virginia Cerdas-Montano y Satya Rosabal-Vitoria
} 


\section{Factores de participación que influyen en el desarrollo del modelo de gestión pedagógica}

Participación inicial en la construcción del modelo de gestión pedagógica, (12 ítems 1, 5) los resultados muestran que de las 72 personas participantes; 39 de ellas inician el proceso (54.17\%) mientras que 33 personas se incorporan posteriormente $(45.83 \%)$.

Con respecto al grupo de 39 participantes iniciales de las etapas de MGP (Figura 1), se denota que el trabajo colaborativo juega un papel importante en la construcción de proyectos escolares afines a las necesidades e intereses de la comunidad educativa (Cerdas Montano, Chen Quesada et ál., 2018).

Mientras que en los datos agrupados de los ítems 12.1 al 12.5, se observa que 33 participantes se incorporan posteriormente. Sin embargo, este grupo ha participado de alguna manera en las cinco etapas del proceso, lo que muestra que los centros promueven acciones de involucramiento del nuevo personal y potencia la participación a largo plazo (Feito Alonso, 2011).

Se muestran a continuación los resultados y análisis del grupo de 72 participantes de cada variable.

\section{Resultados de nivel de participación durante el desarrollo del MGP}

Los resultados que se describen a continuación corresponden a la variable participación en el desarrollo del MGP. Este apartado de la investigación estudia 10 indicadores de análisis estadístico (Figura 2) en relación con esta variable y los datos de frecuencia (Figura 3).

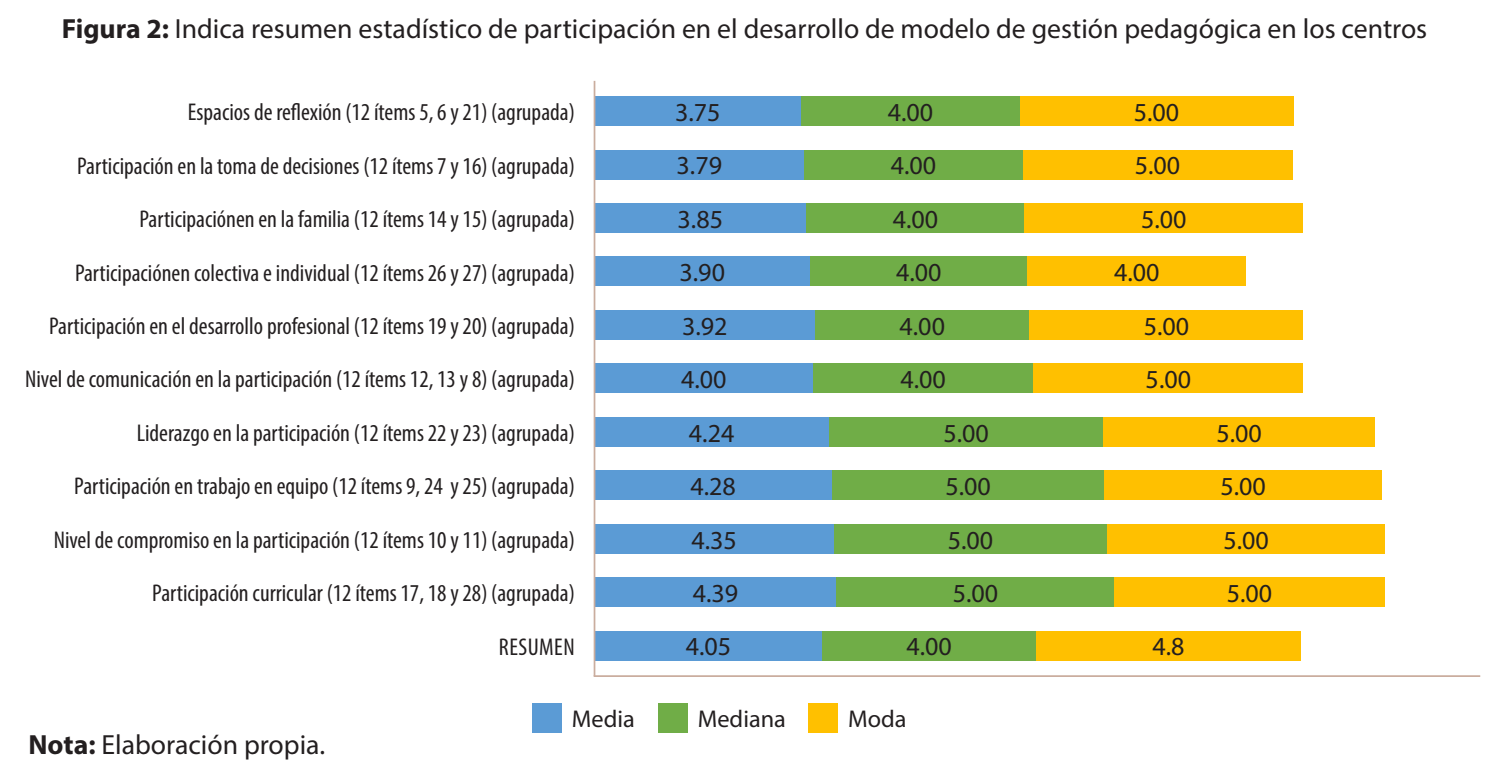


http://doi.org/10.15359/ree.24-2.16

ROR: https://ror.org/01t466c14 Universidad Nacional, Costa Rica

http://www.una.ac.cr/educare

educare@una.cr

Figura 3: Indica resumen de frecuencia de participación en el desarrollo de MGP en los centros

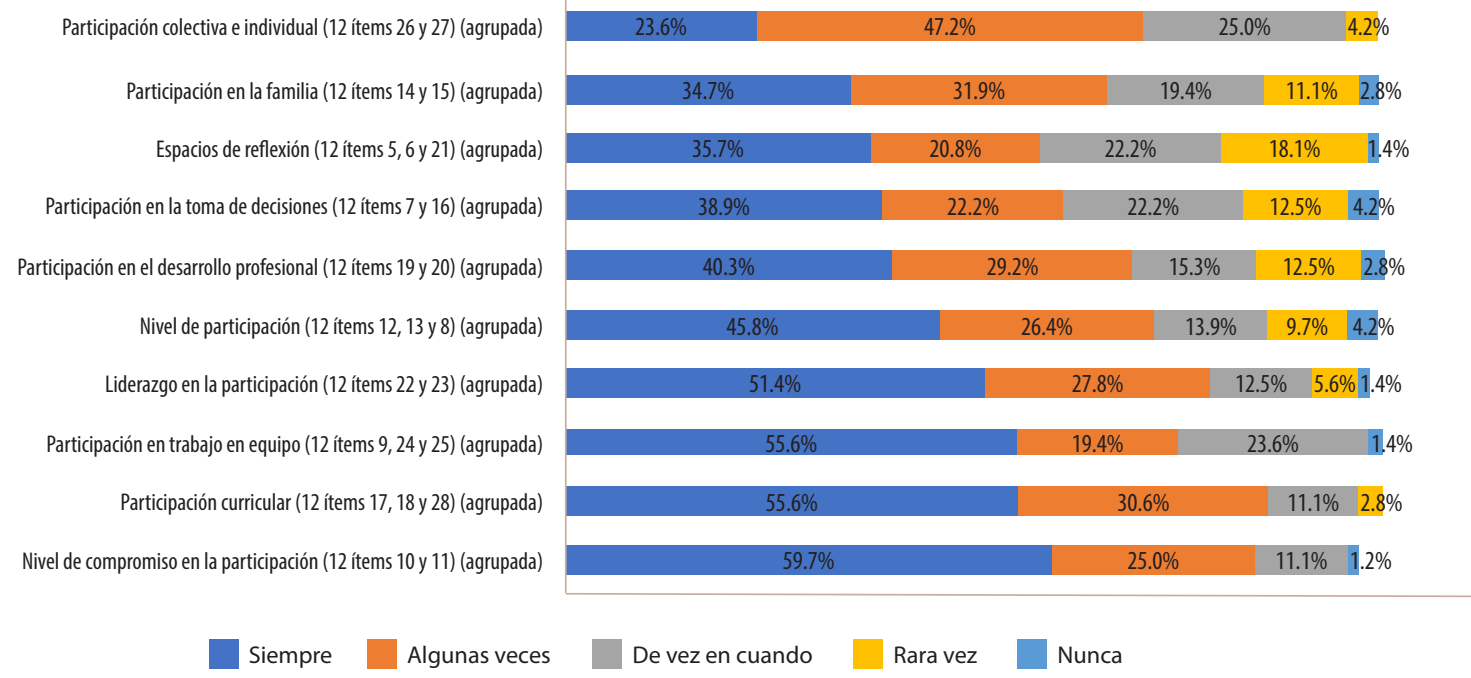

Nota: Elaboración propia.

De acuerdo con los datos presentados en las Figuras 2 y 3 se procede hacer un análisis de los ítems según cada subcategoría establecida.

Participación en espacios de reflexión (12 ítems 5,6,21), muestra que el centro educativo genera espacios de reflexión en su hacer diario, la evaluación y seguimiento de sus propios procesos. Con una media agrupada de 3.75 (Figura 2) y un promedio de frecuencias de $80.5 \%$ (Figura 3). Estos espacios de reflexión permiten integrar las prácticas y conocimiento relevantes y significativos para cada centro (Domènech y Viñas, 1999).

Participación en la toma de decisiones (12 ítems 7, 16), muestra una media de 3.79 (Figura 2) y una frecuencia de $83.3 \%$ (Figura 3) se observa consenso en la toma de decisiones del centro y se considera la opinión de la comunidad educativa. La toma de decisiones colectivas e individuales es para los MGP, un eje central. Según Cerdas Montano, Chen Quesada et ál. (2018), esto permite darle sentido de pertenencia y baja los niveles de resistencia al cambio.

Participación de la familia (12 ítems 14, 15), muestra una media agrupada de 3.85 (Figura 2), y una frecuencia de $34.7 \%$ (Figura 3) evidencia de que los centros promueven canales de comunicación con las familias y abren espacios de reflexión sobre el quehacer del centro educativo. La participación de las familias en el ámbito escolar se convierte en una estrategia de integración requerida para que los MGP tengan funcionalidad. La Unesco (2004) señala que la participación de las familias se hace necesaria en la toma de decisiones, en la solución de los problemas y desafíos que enfrenta la institución educativa. 
Participación en equipo de trabajo (12 ítems 9,24, 25), muestra una media agrupada 4.28 (Figura 2), esto es, el centro fomenta el trabajo en equipo, se toman en cuenta las habilidades de cada miembro y comparten valores con los compañeros y compañeras de trabajo. Cabe destacar que la media más alta 4.47 (ítem 25) corresponde a los valores compartidos entre pares de trabajo. Solo el $1.4 \%$ indicó que no ha participado en trabajo en equipo (Figura 3). Se evidencia que la construcción de valores por parte del colectivo institucional es uno de los componentes principales del MGP. En este sentido, Lussier y Achua (2008) indican que el trabajo en equipo mejora el nivel de responsabilidad e identidad institucional.

Nivel de compromiso en la participación (12 ítems 10, 11), muestra una media agrupada de 4.36 (Figura 2) y una frecuencia de $59.7 \%$ (Figura 3) en la cual se observa que el grupo de participantes se siente identificado con la filosofía del centro y es responsable con lo que sucede, manifiesta estar comprometido. Se concuerda con Pereiran Santana (2013), cuando señalan que el compromiso se ve fortalecido por los niveles de colaboración activa.

Liderazgo en la participación (12 ítems 22, 23), muestra una media agrupada de 4.24, el liderazgo favorece la participación democrática. Por la importancia del liderazgo activo en el desarrollo de MGP, al respecto Lussier y Anchua (2016) indican que el estilo democrático toma especial relevancia, por alentar la participación en la toma de decisiones pedagógicas.

Participación colectiva e individual (12 ítems 26, 27), muestra una media agrupada de 3.90 (Figura 2). La participación eficaz y satisfactoria se caracteriza, según Antúnez (2000), por los principios de corresponsabilidad, cooperación, coordinación, autoridad y democracia.

Nivel de comunicación en la participación (12 items 12, 13, 8), muestra una media agrupada de 4.00 y una moda de 5 (Figura 2), denota que la comunicación ha estado presente para la resolución de conflictos cuando han surgido problemas en el desarrollo del MGP. Además, se promueven canales de comunicación permanentes.

Para que existan resultados efectivos y satisfactorios para los grupos participantes de cada centro, la comunicación es uno de los componentes necesarios en el desarrollo de MGP. Puig et ál. (2003) señalan que la participación democrática de la comunidad educativa es fundamental.

Participación curricular (12 ítems 17, 18, 28), muestra una media agrupada de 4.39 (Figura 2), y una frecuencia de $55.56 \%$ (Figura 3), indica amplia participación de quienes colaboran en el ámbito curricular. El desarrollo de MGP, al implementar proyectos dirigidos al desarrollo pedagógico del centro y contar con una definición clara del rol curricular, contribuyen a que esta participación sea más real y significativa para todas las personas según señala Cerdas Montano, Chen Quesada et ál. (2018).

Participación en el desarrollo profesional (12 ítems 19, 20), muestra una media agrupada de 3.92 (Figura 2) y una frecuencia de $97.2 \%$ (Figura 3), la cual indica que el centro educativo gestiona el 
http://doi.org/10.15359/ree.24-2.16

ROR: https://ror.org/01t466c14 Universidad Nacional, Costa Rica

http://www.una.ac.cr/educare

educare@una.cr

desarrollo profesional. Para Sanguino Mejía (1990), el desarrollo profesional docente y administrativo en los centros implica un proceso activo y de crecimiento de la comunidad educativa.

\section{Factores de actitud frente al cambio que influyen sobre el desarrollo del modelo de gestión pedagógica}

Los factores de actitud frente al cambio que influyen en el desarrollo del MGP se clasifican en siete indicadores: Actitud frente al cambio, nivel de resistencia frente al cambio, cultura organizacional frente al cambio, proceso de acompañamiento frente al cambio, comunicación ante el cambio, familias ante el cambio y el MEP ante el cambio, las cuales se analizarán a continuación.

Figura 4: Resumen estadístico de actitud frente al cambio en el desarrollo del modelo de gestión pedagógica en los centros

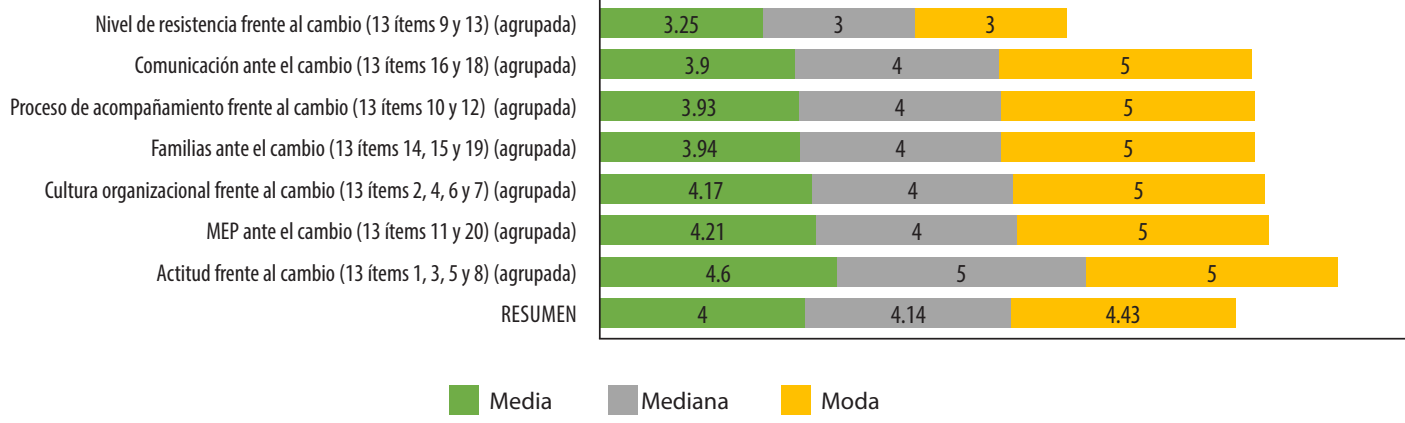

Nota: Elaboración propia.

Figura 5: Indica resumen de frecuencia de participación en el desarrollo de MGP en los centros ivel de resistencia frente al cambio (13 ítems 9 y 13) (agrupada)

Proceso de acompañamiento frente al cambio (13 ítems 10 y 12) (agrupada)

Familias ante el cambio (13 ítems 14, 15 y 19) (agrupada)

Comunicación ante el cambio (13 ítems 16 y 18) (agrupada)

MEP ante el cambio (13 ítems 11 y 20) (agrupada)

Cultura organizacional frente al cambio (13 ítems 2, 4, 6y 7) (agrupada)

Actitud frente al cambio (13 ítems $1,3,5$ y 8 ) (agrupada)

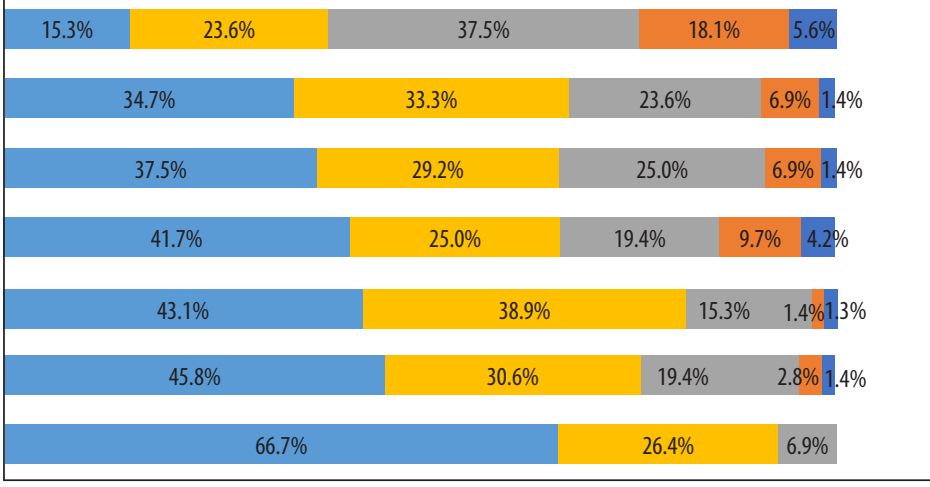

\begin{tabular}{l|l|l|l} 
Siempre & Algunas veces & De vez en cuando & Rara vez
\end{tabular}

Nota: Elaboración propia.

16

Evelyn Chen-Quesada, Virginia Cerdas-Montano y Satya Rosabal-Vitoria

Los artículos de la Revista Electrónica Educare del Centro de Investigación y Docencia en Educación de la Universidad Nacional, Costa Rica, se comparten bajo términos de la Licencia Creative Commons: Reconocimiento, № Comercial, Sin Obra Derivada 3.0 Costa Rica. Las autorizaciones adicionales a las aquí delimitadas se pueden obtener en el correo: educare@una.c 
De acuerdo con los datos presentados en las Figuras 4 y 5, se procede a hacer un análisis de los ítems según cada subcategoría establecida.

Actitud frente al cambio (13 ítems 1, 3, 5, 8), con una media agrupada de 4.60 (Figura 4) se muestra una actitud muy positiva frente al cambio. El grupo de participantes considera que los cambios son necesarios en el centro educativo y se muestra abierto a los procesos que estos conllevan. Por ello, Lussier y Achua (2011) afirman que es importante destacar el compromiso para alcanzar metas colectivas que conllevan esfuerzos y ajustes en las labores diarias de la comunidad educativa.

Nivel de resistencia frente al cambio (13 ítems 9,13) muestra una media de 3.25 (Figura 4) confirma un valor intermedio de resistencia al cambio, es decir, un $15.28 \%$ manifiesta siempre resistencia, un $23.61 \%$ algunas veces, un $37 \%$ de vez en cuando, $18.06 \%$ rara vez y $5.56 \%$ nunca (Figura 5). Como se observa, las personas participantes manifiestan una resistencia al cambio en mayor o menor grado, esto por cuanto los MGP, según Lussier y Achua (2008), representan procesos de cambio, salir del status quo.

Es importante destacar que a pesar de que los grupos participantes mostraron algún tipo de resistencia al cambio, muy pocos refieren que el cambio se estableciera por normativa, por lo que imponerlo por este medio sería contraproducente a los principios y valores en los que se fundamenta el MGP como son la legitimación de cosmovisiones, el bien común, la solidaridad, la confianza, el respeto, la responsabilidad y la reciprocidad (Cerdas Montano, Chen Quesada et ál., 2018).

Cultura organizacional frente al cambio, (13 ítems 2, 4, 6, 7) con una media de 4.17 (Figura 4), se muestra que la cultura organizacional de los centros ha sido favorable con el desarrollo de los MGP. Esto, debido a una cultura de cambio paulatina y de convencimiento, más que de imposición. Además, los participantes se sienten parte de los cambios al ser tomados en cuenta en la toma de decisiones (Lussier y Achua, 2008).

Procesos de acompañamiento frente al cambio (13 ítems 10 y 12) muestra una media agrupada de 3.93 (Figura 4) es decir que $91.66 \%$ de participantes recibió algún tipo de acompañamiento en el proceso de cambio. Cabe indicar, que los cambios fueron promovidos desde el centro educativo, lo cual disminuye los niveles de incertidumbre hacia lo desconocido (Lussier y Achua, 2008).

Aunado a lo anterior, los datos reflejados en el ítem 13.17 sobre el apoyo de la dirección para la asimilación del cambio institucional confirman la importancia del acompañamiento del personal directivo a cargo del centro educativo para lograr mejores efectos. Los resultados muestran que el $83.1 \%$ recibió (Figura 5) algún tipo de apoyo o acompañamiento del directivo escolar en los procesos de cambio. En este sentido el acompañamiento por la parte directiva brinda un apoyo emocional que minimiza la generación de problemas y favorece el enfoque de los esfuerzos de la comunidad educativa hacia las metas trazadas por el colectivo del centro (Bolívar, 2012). 
Comunicación ante el cambio (13 ítems 16 y 18), esta variable muestra los espacios de diálogo para establecer los cambios en el centro educativo. En este sentido el grupo de participantes manifiesta que una media de 3.90 (Figura 4) y una frecuencia de $86.11 \%$ (Figura 5); percibe que la institución brinda los espacios necesarios para comprender los procesos de cambio. La comunicación es un factor clave para el éxito de los procesos de cambio porque el MGP involucra a toda la comunidad educativa (Lussier y Achua, 2011).

Las familias ante el cambio (13 ítems 14, 15 y 19) en relación con el desarrollo de Ios MGP en el centro educativo, la participación de las familias en estos procesos es de suma importancia. Con una media de 3.94 (Figura 4) y una frecuencia de $37.5 \%$ (Figura 5) manifiestan haber participado activamente de procesos de cambio. Es importante retomar el papel de las familias en los procesos de cambio, ya que parte del éxito y la sostenibilidad de un MGP responde precisamente a la comprensión y compromiso de toda la comunidad educativa (Unesco, 2004).

Percepción de nivel de apoyo del MEP (13 ítems 11, 20). En cuanto al nivel de percepción, sobre el apoyo del Ministerio de Educación Pública frente al cambio en el desarrollo del MGP, los resultados develan una media de 4.21 (Figura 4) y una frecuencia de $43.06 \%$ (Figura 5) destaca que los MGP contribuyen al mejoramiento de la oferta educativa y que no riñe con las normativas establecidas por el MEP.

\section{Descripción de las innovaciones metodológicas en el aula, en los espacios colectivos y en la organización administrativa que surgieron con el desarrollo del modelo de gestión pedagógica en el centro educativo}

De la categoría definida como innovaciones, se derivan tres subcategorías: innovaciones metodológicas en el aula, en espacios colectivos y en la organización administrativa.

\section{Innovaciones metodológicas en el aula}

Los resultados que aporta esta categoría se logran clasificar en cinco elementos de análisis: sentido de pertenencia, desempeño docente, creatividad, experiencias de aprendizaje y uso de la tecnología. En este sentido, se puede decir que las innovaciones metodológicas no tienen mayor impacto, si no se generan, a partir de ellas, mejoras tangibles en los procesos educativos (Bolívar, 2012).

A continuación, se presenta un resumen de las respuestas obtenidas, agrupadas según cada elemento de análisis (Tabla 3). 
Tabla 3: Resumen: Innovaciones metodológicas desarrolladas a partir del MGP en el aula

\begin{tabular}{|c|c|}
\hline Subcategoría & Respuesta \\
\hline $\begin{array}{l}\text { Sentido de } \\
\text { pertenencia }\end{array}$ & $\begin{array}{l}\text { Cambios conductuales en estudiantes al respecto de cuidar la institución, mayor sentido de } \\
\text { pertenecía en la parcialidad del personal docente }\end{array}$ \\
\hline & Fortalecimiento del trabajo en equipo, tanto a nivel personal como estudiantil. \\
\hline $\begin{array}{l}\text { Desempeño } \\
\text { docente }\end{array}$ & $\begin{array}{l}\text { Mediación pedagógica. Cambios en forma de dar la clase más interactivas, dinámicas e } \\
\text { innovadoras basadas en el trabajo individual y grupal con plenarias, exposiciones, entre } \\
\text { estudiantes y docentes. }\end{array}$ \\
\hline Creatividad & $\begin{array}{l}\text { Talleres, creatividades e innovaciones de parte de la niñez con mayor participación, cooperación, } \\
\text { iniciativa, tolerancia. }\end{array}$ \\
\hline
\end{tabular}

La atención de las particularidades y necesidades educativas del estudiantado, al incluir a la niñez especial dentro del sistema educativo y también a las personas extranjeras exiliadas.

Al tener una población de niños y niñas casi en su adolescencia, generalmente chicos y chicas que sobrepasan su edad para estar en la escuela, con poco apoyo o nada del hogar, con poco interés. Busco incentivar en ellos responsabilidad, técnicas de estudio, resolución de conflictos, incentivar inteligencias múltiples. Buscando en ellos su conocimiento pleno y que ellos puedan lograr salir adelante.

El niño aprende y comprende cuando se les brinda espacios con sus propias experiencias de vida, y su auto corrección. Aprendizaje significativo fortaleciendo las inteligencias múltiples.

Experiencias Implementación de actividades interactivas con estudiantes: exposiciones, talleres, vivencias. El de aprendizaje juego como estrategia como aprendizaje. Métodos de lecto-escritura; incorporación al proyecto de promoción de la lectura contando con el apoyo de la fundación Aprender y Crecer.

La practica en matemáticas partiendo de la realidad de la población, con la implementación de los nuevos programas de estudio.

Más participación. Se toman en cuenta la opinión de estudiantes, se asignan tareas para mejorar en grupo, se trabaja en mejorar las técnicas de estudios.

Construcción del conocimiento, con una persona facilitadora. Aprendizaje a través de las experiencias adquiridas por el estudiantado mismo con el fin de que cree nuevos conocimientos.

Se implementan actividades basadas en promover el ambiente colaborativo, por el cual nuestro estudiantado reconozca la importancia de la convivencia con nuestros semejantes.

Se ha incrementado el uso de tecnologías digitales, aula, uso de móviles, internet, video beam, en la medición pedagógica.

Tecnologías

Establecimiento de prácticas restaurativas, implementación de las tecnologías en la mediación pedagógica.

Nota: Elaboración propia. 
http://doi.org/10.15359/ree.24-2.16

ROR: https://ror.org/01t466c14 Universidad Nacional, Costa Rica

http://www.una.ac.cr/educare

educare@una.cr

De acuerdo con los resultados expuestos en la Tabla 3, el fortalecimiento del sentido de pertenencia se ha incrementado tanto en el estudiantado como en el personal docente en cuanto al cuido de la institución, debido a que el cuerpo docente es responsable de esta identificación. El trabajo en equipo que se desarrolla en el aula, así como de los espacios de creatividad en la mediación pedagógica reflejan con una amplia variedad de experiencias de aprendizaje tales como metodologías creativas, fortalecimiento de valores como la responsabilidad, mejores técnicas de estudio, desarrollo de proyectos, espacios de educativos colaborativos, actividades lúdicas, apoyados en una gran variedad de actividades que hacen uso de la tecnología en la mediación pedagógica. Es así como un MGP favorece la consolidación del equipo de trabajo del centro educativo, por medio de los procesos colectivos, que necesariamente se desarrollan a lo interno (Gairín, 2000).

Para profundizar, aún más, en las acciones desarrolladas por el personal docente desde la puesta en marcha del MGP en la Tabla 4 se reflejan los resultados.

Tabla 4: Resumen: Descripción del tipo de innovaciones metodológicas a partir de MGP en el aula

\begin{tabular}{ll}
\hline Subcategoría & \multicolumn{1}{c}{ Respuesta } \\
\hline & $\begin{array}{l}\text { Se han colocado afiches en las aulas con los valores institucionales, nuestra misión, visión, } \\
\text { lema. Además, se han promovido los valores en diversas actividades tales como actos cívicos, } \\
\text { presentaciones fuera de la institución, mediante nuestras redes sociales y capacitaciones. }\end{array}$ \\
$\begin{array}{l}\text { Sentido de } \\
\text { pertenencia }\end{array}$ & $\begin{array}{l}\text { El que esos grupos de estudiantes tengan una escuela agradable y con ganas de estudiar junto } \\
\text { con compañeros y compañeras tolerantes al cambio de la inclusión. Respetar la individualidad } \\
\text { y la cooperación entre sí para crear nuevos conocimientos que fomenten la cooperación y el } \\
\text { desarrollo general. }\end{array}$
\end{tabular}

El personal docente hace uso de diferentes metodologías más que todo participativas y en equipo con sus estudiantes para fomentar los valores.

El trabajo en conjunto con los padres y madres de familia y el estado emocional de la niñez.

Los diferentes comités en su plan de trabajo hacen sus propuestas de acuerdo con las necesidades de la institución tomando en cuenta sus prioridades. Se conforma un equipo de la

Desempeño calidad institucional.

docente

En enfoques más contextualizados basados en la realidad comunal y social de estudiantes que generan cambios de actitud.

Trabajo en equipo con la orientadora para brindarles técnicas de estudio, dominio de su estilo de aprendizaje, participación en actividades extracurriculares, siempre y cuando respondan o mejoren en clase. Conocimiento de resolución de conflictos ante casos de drogas, abusos, problemas en el hogar.

continúa 
Atención de estilos de aprendizaje, atención de necesidades educativas por discapacidad, desarrollo de adecuaciones curriculares.

En hacer más dinámicas las lecciones que favorezcan el aprendizaje significativo con más participación activa de cada estudiante. Realizar exploraciones dentro de la institución y motivar la creación de murales, mapas conceptuales, carteles, bailes y canciones, para promover la creación artística.

En la creación de materiales, en la participación de actividades para el crecimiento personal, social, para la comunicación, para el conocimiento de sí mismo con estrategias que respondan

Experiencias a las necesidades estudiantiles.

Lecciones interactivas, más dinámicas, manualidades; para mejorar las condiciones de autoestudio en el estudiantado. Además, de investigación en el aula, de temas de los contenidos del programa por medio de tics, y plenarias.

Refuerzos positivos

- Control del aprendizaje a través de objetivos conductuales

- Libre expresión

- Creación de ambientes y experiencias de desarrollo. Énfasis en el trabajo productivo

- Confrontación social.

En la elaboración de los proyectos en el aula, fomentar la creatividad y amor por la lectura y la

Creatividad escritura, acompañadas de dramatizaciones, formación de cuentos por parte de estudiantes, donde se promueva la práctica de el mejoramiento de la lectura aplicando evaluación de lo logrado en el proceso

Tecnologías

Implementación de software para el aula. Uso de computadora para investigaciones. Se trabaja en red, se permiten espacios para uso del celular en forma pedagógica, se utiliza mayormente el vídeo beam con temas más complejos. Utilización de Smart Tv, videos, programas interactivos, tipo juegos.

Nota: Elaboración propia.

Se evidencia, según los datos de la Tabla 4, que los espacios docentes han permitido el desarrollo de experiencias educativas en torno al currículo que se han enriquecido con contenido novedoso, optimización del espacio para la convivencia e intercambio de conocimiento que promueven valores como la equidad y el género entre estudiantes y docentes.

En cuanto a los espacios recreativos, hay un claro fortalecimiento de la actividad lúdica. En este sentido, Posso Restrepo et ál. (2015) indican:

La lúdica es una manera de vivir la cotidianidad, es decir, de sentir placer y valorar lo que acontece percibiéndolo como acto de satisfacción física, espiritual o mental. La actividad lúdica propicia el desarrollo de las aptitudes, las relaciones y el sentido del humor en las personas. (p.166) 
Al respecto, los espacios recreativos desarrollados en MGP fomentan la diversión, el juego, lo placentero y la sana convivencia entre sus pares.

Los espacios de gestión permiten que la comunidad escolar (estudiantes, docentes, personal administrativo y las familias) desarrolle estrategias conjuntas en la optimización de los recursos. Esto permite que los centros educativos ejecuten proyectos colectivos claves en colaboración de las familias, de utilización de materiales y de organización en equipo del profesorado (Chen Quesada y Vargas Jiménez, 2007).

Con respecto a los espacios de circulación y servicio, hay evidencia en el cumplimiento de la Ley 7600, la cual hace referencia a la Ley de Igualdad de Oportunidades para las personas con Discapacidad (Asamblea Legislativa de la República de Costa Rica, 2019) lo que fortalece la integración de las diferencias y la atención a la diversidad en todas sus dimensiones. Además de la incorporación del alumnado afectado por circunstancias de desventaja.

En cuanto a la descripción brindada por el grupo participante, las innovaciones metodológicas del aula, relacionadas con cada una de las subcategorías anteriores, muestran una variedad de estrategias que evidencian un dinamismo en los procesos educativos desarrollados en el aula. Y es, precisamente en estos espacios, en donde se visualizan, de manera más tangible, los efectos de un modelo de gestión pedagógica, en donde se promueve un conjunto de actividades interrelacionadas desde la gestión de todos los recursos del centro educativo, para el logro de objetivos más operativos, que recaen directamente en las estrategias metodológicas del aula, las cuales dan respuesta a necesidades o resuelven algún problema (Cerdas Montano, Marín Calderón et ál., 2008). De esta manera, el desarrollo de un MGP genera propuestas metodológicas más innovadoras y contextualizadas en su realidad, como lo expresan los sujetos entrevistados, por ejemplo, en la elaboración de los planes de trabajo de los comités, que estos surgen a partir de sus necesidades y tomando en cuenta las prioridades. Estas innovaciones, a su vez, propician un mayor sentido de pertenencia institucional y fomentan la creatividad de la comunidad escolar.

\section{Innovaciones metodológicas en espacios colectivos}

La información que surge de esta subcategoría se clasifica, para su comprensión, en cinco elementos de diferentes tipos de espacio (Chen Quesada y Vargas Jiménez, 2007).

A continuación (Tabla 5), se enumeran una serie de innovaciones metodológicas desarrolladas en los diversos espacios mencionados anteriormente. 
Tabla 5. Resumen: Innovaciones metodológicas desarrolladas a partir del MGP en espacios colectivos

\begin{tabular}{|c|c|}
\hline $\begin{array}{l}\text { Subcatego- } \\
\text { ría }\end{array}$ & Respuesta \\
\hline \multirow{4}{*}{$\begin{array}{l}\text { Espacios } \\
\text { docentes }\end{array}$} & $\begin{array}{l}\text { Diferentes zonas de juego, con actividades con el lema de los valores, clases dinámicas, equidad } \\
\text { de género. }\end{array}$ \\
\hline & $\begin{array}{l}\text { Incorporación de contenidos novedosos en áreas o disciplinas existentes o estrategias de } \\
\text { enseñanza o metodológicas tales como espacio de lectura para la niñez junto con sus docentes. }\end{array}$ \\
\hline & $\begin{array}{l}\text { Mejorar nuestra sala de maestros y maestras haciendo de ella un lugar más agradable. Se } \\
\text { acondicionó la sala y apoyo técnico para la biblioteca. }\end{array}$ \\
\hline & $\begin{array}{l}\text { Cursos, espacios de convivencia con tecnología y en valores, uso de computadoras para trabajo } \\
\text { docente y utilización de la niñez para investigaciones. }\end{array}$ \\
\hline \multirow{2}{*}{$\begin{array}{l}\text { Espacios } \\
\text { recreativos }\end{array}$} & $\begin{array}{l}\text { Se ha tratado de trabajar en recreos más divertidos y con menos violencia. Espacios para merendar } \\
\text { los estudiantes y compartir. Juegos tradicionales en los recreos. Uso de la cancha por días para } \\
\text { evitar golpes y dificultades. Juegos al aire libre, actividades extramuros, metodologías en el juego } \\
\text { incluyendo juegos tradicionales en los recreos. }\end{array}$ \\
\hline & $\begin{array}{l}\text { Áreas de juego, sala de docentes, cubículos para el profesorado, acondicionamiento de la } \\
\text { biblioteca para que los chicos y chicas vean películas, pinten, dramaticen. Adaptan zonas para } \\
\text { juegos como dado, ajedrez, tableros, minibancos, cubos zomas. Han pintado juegos en diferentes } \\
\text { espacios libres de la institución, se pintó y decoró el área de comedor y juegos para fortalecer los } \\
\text { conocimientos adquiridos y como metodología para incentivar el interés de los niños y las niñas. }\end{array}$ \\
\hline \multirow{3}{*}{$\begin{array}{l}\text { Espacios } \\
\text { gestión }\end{array}$} & $\begin{array}{l}\text { Se implementa la aplicación de talleres en las asignaturas que se imparten con la participación de } \\
\text { los padres y madres de familia. }\end{array}$ \\
\hline & $\begin{array}{l}\text { Trabajo en equipo, compañerismo; a través de espacios para socializar entre docentes, actividades } \\
\text { recreativas colectivas a nivel estudiantil }\end{array}$ \\
\hline & El correcto uso del registro y expediente digital, más acompañamiento de la tecnología. \\
\hline \multirow{2}{*}{$\begin{array}{l}\text { Espacios } \\
\text { circulación } \\
\text { y servicios }\end{array}$} & $\begin{array}{l}\text { Adaptación de rampas y baterías de servicio sanitario, aviso de recreo y cambio de lección con } \\
\text { bombillos especiales para población sorda, uso de braille, intérprete para población sorda durante } \\
\text { actividades de la institución. }\end{array}$ \\
\hline & Aula preescolar para niñez sorda. \\
\hline
\end{tabular}

Nota: Elaboración propia, indica resumen de innovaciones metodológicas desarrolladas a partir del MGP en espacios colectivo.

De acuerdo con los resultados de la Tabla 5, sobre las innovaciones metodológicas desarrolladas a partir del MGP en espacios colectivos se observa que los espacios docentes permiten el desarrollo de experiencias educativas en torno al currículo y son enriquecidas con contenido novedoso, optimización del espacio para la convivencia e intercambio de 
http://doi.org/10.15359/ree.24-2.16

ROR: https://ror.org/01t466c14 Universidad Nacional, Costa Rica

http://www.una.ac.cr/educare

educare@una.cr

conocimiento que promueven valores como la equidad y el género entre estudiantes y profesorado (Cerdas Montano, Chen Quesada et ál., 2018).

En cuanto a los espacios recreativos, hay un claro fortalecimiento de la actividad lúdica del estudiantado como marco básico para la construcción del conocimiento, así como fuente de experiencia y comprensión del entorno al contexto educativo. Los espacios recreativos desarrollados en MGP que fomentan la diversión y el juego, fomento de la sana convivencia entre sus pares.

Los espacios de gestión permiten que la comunidad escolar (estudiantes, docentes, personal administrativo y las familias) desarrolle estrategias conjuntas en la optimización de los recursos. Esto, gracias a que los centros educativos desarrollan proyectos colectivos claves, en colaboración con las familias, de utilización de materiales y de organización en equipo del profesorado (Chen Quesada y Vargas Jiménez, 2007).

\section{Innovaciones metodológicas en la organización administrativa}

En relación con la organización administrativa, el estudio devela siete elementos de análisis que permiten la comprensión del impacto del los MGP en los centros educativos participantes, que a continuación se detallan (Tabla 6).

Tabla 6: Resumen: Innovaciones metodológicas desarrolladas a partir del MGP en la organización administrativa

\begin{tabular}{|c|c|}
\hline Subcategoría & Respuesta \\
\hline \multirow[t]{2}{*}{$\begin{array}{l}\text { Organismos de } \\
\text { apoyo }\end{array}$} & $\begin{array}{l}\text { Organización de actividades con la comunidad educativa, junta de educación y comunidad } \\
\text { en general, que cumple con las orientaciones emanadas del MEP en cuanto a participación } \\
\text { inclusiva en todos los ámbitos. Llevan junto con el Comité de Nutrición un excelente control } \\
\text { de los alimentos que solicitan al ente proveedor y se encargan de revisar los pedidos y estar } \\
\text { pendientes de los menús que se le da cada semana a la niñez. }\end{array}$ \\
\hline & $\begin{array}{l}\text { También llevan un calendario de reuniones con agenda. Por lo cual hay una buena } \\
\text { organización para realizar los pedidos de materiales para diferentes actividades o ferias de la } \\
\text { escuela. Esto conlleva a buena proyección de las actividades y a una mejor eficacia. }\end{array}$ \\
\hline \multirow[t]{2}{*}{$\begin{array}{l}\text { Programas de } \\
\text { estudio }\end{array}$} & $\begin{array}{l}\text { En matemáticas el enfoque de resolución de problemas y los nuevos programas y la forma de } \\
\text { planificar la lección; en ciencias el nuevo programa de estudio, aplicando los nuevos métodos } \\
\text { pedagógicos innovadores dentro de la planificación educativa diaria y mensual. Se trabaja de } \\
\text { forma interactiva. Mucha exposición por parte del alumnado y proyectos de investigación. }\end{array}$ \\
\hline & $\begin{array}{l}\text { Implementación del sistema PIAD, establecimiento de equipos de colaboración con los } \\
\text { nuevos programas }\end{array}$ \\
\hline
\end{tabular}

continúa 
Así como este año se implementa una nueva directriz sobre el planeamiento didáctico, los nuevos cambios en evaluación con respecto a la calificación de la materia de Estudios Sociales y Español es el enfoque de conciencia fonológica, en el proceso de lector-escritura Cambios en la en primer grado.

evaluación

La evaluación de trabajos cotidianos se hace más colectiva, promoviendo la participación de todo el grupo; más lúdica, igual las tareas cortas. Donde se complica un poco es que todavía se exige la prueba escrita como medio para evaluar el conocimiento y es un requisito del sistema educativo y los cambios que se promueven son de forma nunca de fondo.

También el uso de medios tecnológicos para que la dirección nos mantengan informados y el uso del laboratorio PIAD, para facilitar nuestras labores.

Tecnologías

Prácticas o herramientas tecnológicas que nos brinda la biblioteca y trabajo en equipo, clases en donde se involucren las tecnologías.

Coordinación de matrícula y atención de estudiantes con necesidades educativas especiales, coordinación activa de documentación oficial concerniente a la atención de estudiantes con

Comités

coordinación particularidades y necesidades especiales, entre otros

Reuniones de personal donde se da espacios para que los diferentes comités capaciten o den información al personal docente, administrativo y apoyo a padres de familia. Usando los recursos tecnológicos luego al enviar a los correos la información abordada.

Directrices del MEP Siguiendo directrices del MEP, la innovación es un poco restringida

Comunicaciones Una comunicación más asertiva con docentes, personal administrativo, alumnado y padres de familia.

Nota: Elaboración propia, indica resumen de innovaciones metodológicas desarrolladas a partir del MGP en la organización administrativa.

Como se puede observar en la Tabla 6, se destacan siete innovaciones metodológicas desarrolladas a partir del MGP: organización administrativa, relación con organismos de apoyo, programas de estudio, cambios en la evaluación, tecnologías, comités y mejoras en la comunicación para cumplir con los lineamientos establecidos por el MEP, en donde el papel de la persona directiva juega un rol importante para dinamizar e integrar estos esfuerzos desde una dimensión pedagógica. En este sentido, los procesos organizativos administrativos de los centros tienen incidencia en la dirección pedagógica (Puig et ál., 2003), favoreciendo, de esta manera, un proceso de doble vía en el fortalecimiento de las capacidades de la persona directiva, como de la organización.

Se pudo observar, en términos generales, que los resultados de las tres categorías (participación, actitud frente al cambio y las innovaciones) son elementos interrelacionados y 
necesarios para una comprensión global de los MGP. Los resultados de participación apuntan a que los espacios de reflexión son requisito para la toma de decisiones, generar compromiso, trabajo en equipo y contar con un plan de desarrollo profesional; todo ello dirigido a mejorar las actitudes frente al cambio y, por consiguiente, disminuir las resistencias. Esto da a lugar a promover un ambiente organizacional que fomente la innovación en todos sus ámbitos para responder a las necesidades, problemáticas e intereses de la institución.

\section{Conclusiones}

De acuerdo con los objetivos del estudio que contemplan la participación, la actitud frente al cambio y las innovaciones metodológicas, estas tienen un nivel de relevancia en el grupo de participantes para desarrollar un modelo calificado de gestión pedagógica.

Es importante destacar que las personas participantes de este estudio, en su mayoría ( 80.6 $\%$ ) se encuentran nombradas por el MEP en una condición de propiedad de su plaza, lo cual garantizó su permanencia durante el desarrollo del MGP, y generó una mayor comprensión sobre las problemáticas institucionales según el contexto histórico y social del centro educativo.

A continuación, se detallan las conclusiones que surgen de esta investigación por cada uno de los objetivos planteados inicialmente.

En relación con el primer objetivo que refiere a la identificación del nivel de participación de las personas que conforman el centro educativo en el desarrollo del MGP, se visualiza que la participación se orienta hacia espacios de reflexión para la toma de decisiones y trabajo en equipo en la construcción, evaluación y seguimiento de proyectos educativos pertinentes y contextualizados en la realidad de cada centro.

Se muestra que hay preferencia del grupo de participantes por el trabajo colectivo sobre el individual, a pesar de que ambos tipos son requeridos en los centros para el desarrollo del MGP. El trabajo colectivo genera otras habilidades que son complemento para el buen desempeño de la participación, tal como la comunicación, resolver problemas o expresar acuerdo o desacuerdos, así como el liderazgo que favorece la participación de cada integrante, además de la participación democrática que incrementa el compromiso y la responsabilidad en la gestión curricular.

En relación con el segundo objetivo sobre los procesos de cambio en el marco de los MGP, es importante destacar la necesidad de que la comunidad educativa sea informada del proceso global que se pretende llevar a cabo, por cuanto el compromiso de sus miembros es una piedra angular en el desarrollo de los MGP.

La resistencia frente al cambio es una condición que se experimenta en las organizaciones cuando enfrentan procesos que alteran la forma que, comúnmente, se utilizan para responder

\footnotetext{
Evelyn Chen-Quesada, Virginia Cerdas-Montano y Satya Rosabal-Vitoria

Los artículos de la Revista Electrónica Educare del Centro de Investigación y Docencia en Educación de la Universidad Nacional, Costa Rica, se comparten bajo términos de la Licencia Creative Commons: Reconocimiento, No Comercial, Sin Obra Derivada 3.0 Costa Rica. Las autorizaciones adicionales a las aquí delimitadas se pueden obtener en el correo: educare@una.cr
} 
las demandas del contexto. Sin embargo, la presencia y acompañamiento del personal directivo escolar es un elemento que interviene de manera positiva para minimizar estas residencias. La confianza de la comunidad educativa en el liderazgo de quien ejerce la dirección del centro es medular en estos procesos de cambio.

Con respecto a la afectación de la cultura organizacional frente a los cambios que implica el desarrollo de los MGP, son evidentes en el tanto la organización está sometida a procesos permanentes de cambio y estos conllevan ajustes en todos los espacios de interacción de la comunidad educativa. Cabe destacar que la comunicación juega un papel relevante para que esta cultura organizacional migre hacia ambientes inclusivos, de respeto hacia todos sus miembros y en donde los significados de la información sean percibidos desde espacios colectivos que permitan una comprensión fácil y oportuna de los cambios que se suscitan.

Los cambios de cara a los procesos de desarrollo de MGP deben contemplar tanto a las personas participantes internas como al personal docente y directores o directoras, pero de igual manera las familias y el estudiantado que juntos conforman la comunidad educativa. Los MGP como proceso de construcción colectiva provocan cambios paulatinos y su sostenibilidad depende del compromiso y comprensión de sus miembros, por lo que la participación de la comunidad educativa representa uno de sus mayores desafíos.

Los MGP favorecen no solo una afectación hacia la organización administrativa, sino que conlleva el repensar la oferta educativa de una manera integral, lo cual puede generar cambios en los diferentes espacios áulicos, además de repercutir en la cultura organizacional concretamente en aspectos como: sentido de pertenencia, desempeño docente, creatividad, uso de las tecnologías en apoyo a la mediación pedagógica, relación con las familias y la comunidad, espacios colectivos, entre otras.

En relación con el tercer objetivo que refiere a la innovación, los MGP promueven la participación de la comunidad educativa, por tanto, los procesos de innovación se ven favorecidos desde los espacios colectivos para la construcción de propuestas que respondan a las necesidades e intereses de cada contexto, generando centros educativos inclusivos, que trabajan de manera intencionada la transformación social con miras a una mejor calidad de vida.

El impacto de las variables de participación, cambio e innovación desde el desarrollo de los MGP en los centros educativos participantes es evidente, como lo demuestran los resultados de la investigación. A pesar de que se hace el análisis desde cada variable o categoría de manera independiente en este estudio, se considera necesario aclarar que los procesos educativos deben de ser asumidos de manera integral por ser un proceso articulado con otros. 


\section{Declaración de material complementario}

El preprint del artículo está disponible en: https://www.repositorio.una.ac.cr/ handle/11056/15085

\section{Referencias}

Amadio, M. Opertti, R. y Tedesco, J. C. (2015). El currículo en los debates y en las reformas educativas al horizonte 2030: Para una agenda curricular del siglo XXI. UNESCO-IBE. http://disde. minedu.gob.pe/handle/123456789/4267

Antúnez, S. (2000). La acción directiva en las organizaciones escolares. Análisis y propuestas. Horsori.

Asamblea Legislativa de la República de Costa Rica. (01 de agosto de 2019). Ley 7600. Ley de igualdad de oportunidades para las personas con discapacidad. http://www.pgrweb.go.cr/ scij/Busqueda/Normativa/Normas/nrm texto completo.aspx?param1=NRTC\&nValor1=1 \&nValor $2=23261 \&$ nValor $3=117926 \&$ strTipM $=$ TC

Bolívar, A. (2012). Políticas actuales de mejora y liderazgo educativo. Ediciones Aljibe.

Cerdas Montano, V., Chen Quesada, E. y Rosaba Vitoria, S. (2018). Hacia una nueva comprensión de cómo hacer gestión pedagógica. Universidad Nacional.

Cerdas Montano, V., Marín Calderón, A. y Vargas Jiménez, I. (2008). Modelos de gestión pedagógica, en zonas de atención prioritaria: Análisis de una experiencia. Revista Electrónica Educare, 12(2), 9-29. https://doi.org/10.15359/ree.12-2.1

Chen Quesada, E. y Vargas Jiménez, I. (2007). Administración de recursos institucionales en centros educativos. Editorial Universidad Nacional.

Creswell, J.W. (2009). Research design: Qualitative, quantitative, and mixed methods approaches. Sage.

Domènech, J. y Viñas, J. (1999). La organización del espacio y del tiempo en el centro educativo. Graó.

Feito Alonso, R. (2011). Los retos de la participación escolar: Elección, control y gestión de los centros educativos. Morata.

Gairín, J. (2000). El proyecto educativo y el desarrollo del currículum. En M. Rovira Gabarró (selección de textos), El proyecto educativo de la institución escolar (pp. 21-30). Graó.

Hernández Sampieri, R., Fernández Collado, C. y Baptista Lucio, M. del P. (2010). Metodología de la investigación ( $5^{\mathrm{a}}$ ed.). McGraw-Hill. 
Hernández Sampieri, R., Fernández Collado, C. y Baptista Lucio, M. del P. (2014). Metodología de la investigación (6 $6^{\mathrm{a}} \mathrm{ed}$.). McGraw-Hill.

Lussier, R. N. y Achua, C. (2008). Liderazgo. Teoría, aplicación y desarrollo de habilidades. Cengage Learning Editores.

Lussier, R. N. y Achua, C. F. (2011). Liderazgo: Teoría, aplicación y desarrollo de habilidades. Cengage Learning Editores. https://issuu.com/cengagelatam/docs/liderazgo lussier issuu

Lussier, R. N. y Achua, C. (2016). Liderazgo. Teoría, aplicación y desarrollo de habilidades. CENGAGE Learning Editores.

Murillo Torrecilla, F. J. (2006). Una dirección escolar para el cambio: Del liderazgo transformacional al liderazgo distribuido. Revista Electrónica Iberoamericana sobre Calidad, Eficacia y Cambio en Educación, 4(4e), 11-24. http://www.redalyc.org/pdf/551/55140403.pdf

Pereira Santana, A. E. (2013). Liderazgo líquido: Una propuesta para enfrentar la incertidumbre y riesgo. Pensamiento y gestión, 37, 97-113. http://dx.doi.org/10.14482/pege.37.7022

Posso Restrepo, P., Sepúlveda Gutiérrez, M., Navarro Caro, N. y Laguna Moreno, C.E. (2015). La lúdica como estrategia pedagógica para fortalecer la convivencia escolar. Lúdica Pedagógica, 21, 163-174. https://doi.org/10.17227/01214128.21ludica163.174

Puig, J. M., Martín, X., Escardíbul, S. y Novella, A. M. (2003). Cómo fomentar la participación en la escuela. Propuestas de actividades. Graó.

Rosabal Vitoria, S., Gamboa Jiménez, A., Cerdas Montano, V., Hernández Gómez, R. I., Murillo Mora, Y. y Vargas Jiménez, I. (2013). Modelos de gestión pedagógica en la escuela primaria: Un aporte en la calidad de la educación. Manuscrito inédito.

Sanguino Mejía, S. del C. (1990). Un programa de capacitación y actualización docente como medio para la profesionalización de la enseñanza. Educación y Ciencia, 1(1), 53-58. http:// www.educacionyciencia.org/index.php/educacionyciencia/article/view/12

Segura Bonilla, O. (2010). Universidad y desarrollo: Desafíos en el siglo XXI. Publicaciones e impresiones de la Universidad Nacional.

Unesco. (2004). Participación de las familias en la educación infantil latinoamericana. Trineo http://unesdoc.unesco.org/images/0013/001390/139030s.pdf 